Jurnal Konstruksi Hukum | ISSN: XXXX | E-ISSN: XXXX

Vol. 1, No. 2, Oktober 2020, Hal. 281-285| Available Online at https://www.ejournal.warmadewa.ac.id/index.php/jukonhum

DOI: https://doi.org/10.22225/jkh.1.2.2597.281-285

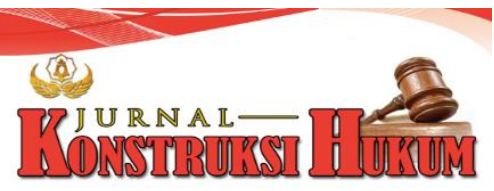

\title{
INFOSANKSI PIDANA PENYALAHGUNAAN PENGANGKUTAN BAHAN BAKAR BERSUBSIDI
}

\author{
I Dewa Gede Sastra Buwana, I Wayan Rideng, I Ketut Sukadana \\ Fakultas Hukum Universitas Warmadewa, Denpasar, Bali, Indonesia \\ Email: dewagede50@gmail.com
}

\begin{abstract}
Abstrak
Migas merupakan sumber daya alam yang dikuasai oleh negara dan merupakan sumber komoditas vital yang memegang peranan penting dalam setiap kegiatan-kegiatan manusia. Adanya penyalahgunaan pengangkutan dan niaga bahan bakar yang disubsidi pemerintah oleh oknum tertentu dapat merampas hak-hak masyarakat kurang mampu dan mengakibatkan kerugian terhadap negara. Penelitian ini menerangkan bagaimanakah pengaturan pengangkutan atau perniagaan bahan bakar bersubsidi dan mengetahui sanksi pidana pelaku penyalahgunaan bahan bakar bersubsidi. Metode penelitian yang digunakan adalah penelitian Hukum Normatif. Pendekatan masalah secara Perundang-undangan yaitu menganalisa dari sudut peraturan Perundang-undangan dan teori yang relevan. Sumber bahan hukum dalam penelitian ini berupa bahan hukum primer dan sekunder. Teknik pengumpulan bahan hukum diperoleh dari bahan-bahan hukum kepustakaan dengan cara mengumpulkan, membaca dan mencatat bahan-bahan hukum yang berhubungan dengan tindak pidana penyalahgunaan bahan bakar bersubsidi. Hasil penelitian ini adalah pertama, Pengaturan perlindungan hukum dan pengawasan sudah diatur sesuai ketentuan Pasal 46 UU No 22 tahun 2001 Minyak dan Gas bumi. Kedua, sanksi putusan hukum terhadap pelaku penyalahgunaan bahan bakar bersubsidi: kasus di Pengadilan Negeri (PN) Gianyar nomor perkara Nomor 153/Pid.Sus/2017/PN. Gin bersifat kumulatif, sebagaimana diatur dalam Pasal 55 UU RI No 22 Tahun 2001, yakni diberi putusan berupa dihukum penjara berkisar 10 (sepuluh) bulan dan denda sejumlah 2 juta rupiah dengan ketentuan apabila denda tersebut tidak dibayar diganti dengan pidana kurungan penjara selama 2 (dua) bulan.
\end{abstract}

Kata Kunci: Bahan bakar bersubsidi; Penyalahgunaan; Tindak pidana

\begin{abstract}
Oil and gas is a natural resource controlled by the state and is a source of vital commodities that play an important role in every human activity. The misuse of the transportation and trade of fuel subsidized by the government by certain individuals can take away the rights of the less fortunate and result in losses to the state. This research explains how to arrange the transportation or commercialization of subsidized fuel and to find out the criminal sanctions for the perpetrators of misuse of subsidized fuel. The research method used is Normative Law research. The statutory approach to the problem is to analyze from the point of view of statutory regulations and relevant theories. Sources of legal materials in this study are primary and secondary legal materials. The technique of collecting legal materials is obtained from legal literature materials by collecting, reading and recording legal materials related to the crime of misuse of subsidized fuels. The results of this study are first, the regulation of legal protection and supervision has been regulated in accordance with the provisions of Article 46 of Law No. 22 of 2001 on Oil and Gas. Second, legal sanctions against perpetrators of misuse of subsidized fuel: case at the Gianyar District Court (PN) case number 153 / Pid.Sus / 2017 / PN. Gin is cumulative in nature, as regulated in Article 55 of the Republic of Indonesia Law No. 22 of 2001, namely given a verdict in the form of a prison sentence of 10 (ten) months and a fine of 2 million rupiahs provided that if the fine is not paid, it is replaced by imprisonment for 2 (two) month.
\end{abstract}

Keywords: Subsidized fuel; Abuse; Criminal act

\section{PENDAHULUAN}

Indonesia merupakan negara dengan kedaulatan hukum sebagai ideologi yang serta merta menciptakan ketertiban, kenyamanan, keamanan, keadilan masyarakatnya, dimana hukum tersebut mengikat masyarakatnya dalam setiap perlakuan masyarakat guna mengontrol sistem pemerintahan dan untuk itu 
adanya HAM dan pembagian kekuasaan serta pengawasan terkait. Negara ini terdiri dari beberapa pulau serta kaya dengan hasil bumi/alam, salah satunya yakni migas (minyak dan gas) yang dominan pada masyarakat indonesia dalam penghasilannya taraf masyarakat terutama (Hardiwinoto, 2010). Indonesia menghasilkan migas dengan cukup besar dari pertambangan-pertambangan di indonesia sendiri sebagai SDA terbesar dan pengolahannya disistematis oleh pemerintah Indonesia sendiri (Rumokoy, 2016).

Migas dapat ditemui dan terlihat sesuai kondisi geologis penyebutannya yaitu jebakan-jebakan struktural dan stratigrafic (structural and stratigraphic traps). Mengenai jebakan-jebakan itu yakni pada batuan-batuan yang dalam letaknya pada titik reservoir yang bisa atau dapat menempatkan pada wadah minyak dan fluida sehingga gas tersebut dapat terakumulasi. Migas bumi itu dapat terletak dimana saja didalam lapisan bawah tanah. Akan tetapi dalam hal tersebut pada hakikatnya/keseluruhannya dapat dijumpai pada titik kedalaman di bawah permukaan tanah dari lapisan-lapisan tersebut (Prihatini, 2013).

Di indonesia pengelolaan migas dikontrol oleh pemerintah itu sendiri dan dikuasai oleh negara guna melancarakan pemakaian serta pendistribusiannya ke masyarakat luas (Sang Ayu Putu Rahayu, 2017). Adapun kegiatan-kegiatan tersebut antara lain untuk usaha mikro, usaha perikanan, usaha pertanian, transportasi dan pelayanan umum sebagaimana yang tercantum dalam Lampiran PERMEN Energi dan SDM mineral RI No 18 Tahun 2013 tentang harga jual eceran jenis bahan bakar tertentu untuk konsumen pengguna tertentu. Sehingga pada Negara berkembang seperti Indonesia sangat melindungi dan mengawasi penyaluran dan peredaran sumber daya alam yang tidak dapat diperbaharui tersebut.

Pemerintah mengontrol Migas yang diolah sedemikian rupa ke masyarakat dikarenakan migas bumi merupakan kebutuhan yang sangat langka namun tetap saja dipergunakan sehari hari, dengan hal tersebut UU No 32 tahun 2009 mengenai upaya perlindungan serta pengelolaan dari pemerintah secara sistematis dan terpadu guna melestarikan fungsi lingkungan utamanya alam dalam pemanfaatan, perencanaan, dan sebagainya. Seperti UU yang lainnya, UU No 22 tahun 2001 tentang MIGAS memuat sanksi-sanksi yang terkandung jika dalam pendistribusian migas tersebut terdapat kelalaian pelanggaran yang dapat merugikan pihak-pihak terkait atau negara, baik sanksi administratif maupun sanksi pidana sesuai dengan pasal 51 sampai pasal 56 dimana pemerintah secara tegas harus menegakkan upayaupaya kontrol migas. Usaha pendistribusian suatu migas dari satu daerah ke daerah lain disesuaikan dengan harga - harga yang telah ditetapkan antara bahan bakar industri dengan subsidi agar penyimpangan antara berbagai usaha migas ini tidak bertentangan dengan ketentuan.

Ada beberapa penelitian terdahulu terkait penelitian ini yaitu Resalane \& Hartiwiningsih, (2014) tentang kajian terhadap tindak pidana pengangkutan bahan bakar minyak tanpa izin usaha pengangkutan, selanjutnya Juhara et al., (2018) mengungkapkan Penerapan hukum pidana terhadap tindak pidana pengangkutan, penyimpanan dan perniagaan bahan bakar minyak yang disubsidi tanpa izin, lebih tepat digunakan Pasal 53 Undang-Undang Nomor 22 Tahun 2001, karena dalam ketentuan tersebut dijelaskan secara rinci mengenai perbuatan pengangkutan dan Niaga tanpa Izin Usaha Niaga. Penelitian lain tahun 2019 mengkaji tentang penegakan hukum penyalahgunaan pengangkutan bahan bakar minyak bersubsidi di provinsi riau berdasarkan undang-undang minyak dan gas bumi (Julkifli, 2019). Dari penelitian terdahulu masih belum menjamin pengurangan tindakan penyalah gunaan bahan bakar minyak, oleh sebab itu penelitian ini didesain untuk menjelaskan pengaturan pengangkutan dan perniagaan bahan bakar bersubsidi dan mengetahui sanksi pidana pelaku penyalahgunaan bahan bakar bersubsidi

\section{METODE PENELITIAN}

Penelitian ini didesain dengan penelitian hukum normatif yaitu melakukan pengkajianya berdasarkan norma dan bahan-bahan hukum dari literatur. Sumber bahan hukum dalam penelitian ini berupa sumber bahan hukum primer, sekunder dan tersier. Bahan hukum premier merupakan sumber bahan hukum yang mempunyai kekuatan mengikat berupa peraturan perundang-undangan yang berlaku dan ada kaitannya dengan permasalahan yang dibahas, yaitu berupa Undang-undang Dasar Negara RI Tahun 1945 dan UU No 22 Tahun 2001 tentang Minyak dan Gas Bumi. Bahan hukum sekunder yaitu bahanbahan hukum yang diperoleh dari pengkajian kepustakaan (Library research) yaitu dengan membaca buku-buku hukum, jurnal-jurnal hukum, surat kabar dan juga dari internet yang berkaitan dengan pelanggaran Penyalahgunaan pengangkutan dan atau niaga bahan bakar minyak (gas LPG) yang disubsidi oleh pemerintah sebagai permasalahan yang akan di bahas. Bahan Hukum Tersier yaitu bahan- 
bahan hukum yang diperoleh dari kamus hukum, kamus bahasa, ensiklopedia, dan ilmu lain yang terkait. Teknik pengumpulan data diperoleh dari bahan-bahan hukum kepustakaan dengan cara mengumpulkan, membaca dan mencatat bahan-bahan hukum yang berhubungan dengan Tindak Pidana penyalahgunaan Bahan Bakar Bersubsidi. Selanjutnya bahan yang terkumpul dianalisis dan disusun secara sistematis dengan menggunakan Argumentastai hukum secara deduktif yaitu penerapan norma ke dalam kasus-kasus dan induktif analitik yaitu kasus-kasus digeneralisasi untuk menjadi normanorma

\section{HASIL DAN PEMBAHASAN}

\section{Pengaturan Pengangkutan dan Perniagaan Bahan Bakar Bersubsidi}

Perpindahan suatu barang selalu menggunakan jasa pengangkutan dari satu tempat ketempat lain, hal tersebut sudah disepakati/disetujui. Dalam pasal 1 huruf (g) PPRI No 67 Tahun 2002 tentang badan pengatur penyediaan dan pendistribusian BBM dan kegiatan usaha pengangkutan Gas bumi melalui pipa memuat definisi pengakutan itu sendiri yakni sebagai berpindahnya migas bumi dari tempatnya/penampung menggunakan alat pengangkut migas untuk didistribusikannya ke tempat lain atau ketempat pengolahan migas tersebut. PPRI No 67 Tahun 2002 tentang badan pengatur penyediaan dan pendistribusian bahan bakar minyak dan kegiatan usaha pengangkutan gas bumi melalui pipa. Peraturan hukum pengangkutan yakni mencangkup Undang-undang pengangkutannya, perjanjian dalam pengangkutannya, konvensi internasional dimana mengenai pengakutan internasional, ternyata cara pengangkutan baik dalam darat seperti kereta api, laut/perairan dan udara. Peraturan hukum pengangkutan juga mengenai asas/ norma atau teori guna mempraktekan hukum dalam pengangkutan itu sendiri baik untuk didistribusikan ataupun diolah kembali serta secara jelas dikontrol oleh pemerintah dengan memenuhi ketentuan dari Undang-Undang yang berlaku.

Niaga merupakan kegiatan pengangkutan dimana adanya proses usaha jual beli atau jasa guna memperoleh keuntungan, menggunakan alat pengangkutan niaga (Randang, 2015). Adanya imbalan yang diberikan dalam proses pengangkutan yang dilakukan dan adanya pemnbayaran-pembayaran terhadap pihak terkait sebagai jasa pengangkutan. Berdasarkan UU RI No 22 Tahun 2001 tentang Migas Bumi, yang dimaksud dengan bahan bakar minyak yakni bahan bakar yang berasal dan diolah dari minyak bumi, sedangkan yang dimaksud dengan Pengangkutan yakni suatu berpindahnya migas atau olahan alam lain dalam suatu kegiatan tertentu dalam kinerja penampungan dari suatu tempat ketempat lain baik melalui pipa-pipa transimisi dan/ atau distribusi guna eksport import (M. Ridwan \& Fitriani, 2010).

Pengaturan tentang pengangkutan ini sudah diatur pada Pasal 46 UU No 22 Tahun 2001 mengenai Migas bahwa pengawasan dalam sistematis pendistribusian tersebut pelaksanaannya dilakukan oleh Badan Pengatur yang ditentukan oleh UU yakni pasal 8 ayat 4 utamanya penyediaan dan penditribusian migas. fungsi badan sesuai ayat 1 sebagai pengaturan dalam tersedianya migas dalam upaya penditribusiannya dijamin oleh pemerintah keseluruhan di dalam negeri untuk meningkatkan pemanfaatan kelancarannya. Tugas Badan itu sendiri sesuai ayat 1 dijelaskan adanya penetapan tentang ketersediaannya ataupun penditribusiannya yakni migas serta pencadangan migas nasional ataupun ointernasional guna dalam pemanfaatan dalam pengangkutan/penyimpanan yang didstribusikan kedepannya, tarif pengangkutan itu sendiri ditentukan sesuai dengan syarat dan ketentuan yang berlaku utamanya migas untuk masyarakat ataupun rumah tangga. Pengaturan badan serta fungsi tersebut sesuai ayat 1 meliputi pengawasan dalam bidangnya serta merta sesuai ketentuan pada ayat 3 .

\section{Sanksi Pidana Pelaku Penyalahgunaan Bahan Bakar Bersubsidi}

Sanksi pidana merupakan suatu hukuman sebab akibat artinya ada kasus dan ada akibatnya (Kalensang, 2016). Terdakwa apa bila terbukti melakukan tindak pidana menyalahgunakan pengangkutan, denagan tujuan memperoleh suatu keuntungan/laba dengan sistematis merugikan pihak-pihak terkait baik perseorangan badan usaha, dengan adanya suatu kerugian terhadap pihak terkait ataupun masyarakat maka Negara perlu mengontrol seperti halnya pengoplosan migas yang dalam kegiatan ini sering dalam masyarakat Indonesia. Seperti pada kasus Candra Kurniadi dimana terdakwa telah mengoplos tabung gas guna dijual kembali kepada masyarakat sekitar serta telah melaksanakan usaha yang illegal dalam UU Migas. Terbukti telah melancarkan usaha tanpa izin sesuai pasal 23, memperoleh keuntungan untuk 
pribadi dengan cara yang ilegal/melanggar ketentuan UU maka hal tersebut telah disidangkannya Candra Kurniadi dan dijatuhkan hukuman selama 10 bulan penjara dan denda sejumlah 2 juta rupiah.

Didasari dari fakta yang diperoleh dalam persidangannya terdakwa Candra Kurniadi melancarkan aksinya bertujuan untuk kegiatan jual beli dalam proses pengangkutan dan penyimpanan, pemindahan/pengoplosan migas yaitu LPG $3 \mathrm{~kg}$ menjadi $12 \mathrm{~kg}$, guna meraup keuntungan untuk ekonomis pribadi. Fakta dan keadaan pada persidangan terdakwa telah melakukan kegiatan jual beli dalam proses pengangkutan/ pemindahan atau pengoplosan, sebagaimana tujuan terdakwa untuk memproleh keuntungan pribadi, sehingga Hakim menjatuhkan pidana terhadap terdakwa dengan pidana penjara selama 10 (sepuluh) bulan dan denda sejumlah 2 juta rupiah dengan ketentuan apabila denda tersebut tidak dibayar diganti dengan pidana kurungan selama 2 (dua) bulan.

\section{SIMPULAN DAN SARAN Simpulan}

Berdasarkan hasil penelitian apat disimpulan bahwa Pengaturan perlindungan hukum dan pengawasan sudah diatur sesuai ketentuan Pasal 46 UU No 22 Tahun 2001 Minyak dan Gas bumi. Badan yang berhubungan dengan pengatur sistematis pengangkutan dan pengolahan migas ini secara terstruktur dijalankan sesuai dengan pasal 46 UU No 22 Tahun 2001 ini. Fungsi Badan Pengatur seperti pada UU Migas dalam ayat kesatuyakni pengaturan guna ketersediaannya/distribusikannya migas Bumi yang dikontrol negara/ pemerintah seharusnya dapat menjamin di seluruh wilayah Negara Kesatuan RI serta meningkatkan pemanfaatan gas bumi di dalam negeri, selanjutnya Sanksi putusan hukum terhadap pelaku penyalahgunaan bahan bakar bersubsidi: kasus di Pengadilan Negeri (PN) Gianyar nomor perkara Nomor 153/Pid.Sus/2017/PN.Gin bersifat kumulatif, sebagaimana diatur dalam Pasal 55 UU RI No 22 Tahun 2001, yakni diberi putusan berupa dihukum penjara berkisar 10 (sepuluh) bulan dan denda sejumlah 2 juta rupiah dengan ketentuan apabila denda tersebut tidak dibayar diganti dengan pidana kurungan selama 2 (dua) bulan.

\section{Saran}

Adapun yaang disarankan oleh peneliti yaitu sebaiknya pemerintah kabupaten daerah harus menjamin kebutuhan masyarakat khususnya dalam kebutuhan bahan bakar karena kesejahteraan masyarakat tergantung dengan kebijakan yang keluar dari pemerintah pusat itu sendiri, selanjutnya Masyarakat harus paham dengan adanya kebijakan gas LPG yang disubsidi oleh pemerintah serta menghindari penyalah gunaan gas LPG yang bersubsidi tersebut untuk kepentingan pribadi. Masyarakat sebaiknya memahami bahwa pemerintah mengeluarkan kebijakan berupa tabung gas LPG tersebut untuk masyarakat kita yang kurang mampu atau bisa dikatakan kalangan masyarakat miskin. Pemilik usaha utamanya dalam bidang pendistribusian migas itu sendiri agar tidak memakai cara kotor karena bagaimana pun segala hal yang berkaitan dengan penindakan migas sudah ada ketentuan-ketentuan dari negara yang secara terus menerus dikontrol dan di tindak lanjuti.

\section{DAFTAR PUSTAKA}

Hardiwinoto. (2010). Analisis Deskriptif Kondisi Ekonomi Penambangan Minyak Tanah Mentah (Crude Oil) Tradisional di Kecamatan Sambong dan Kecamatan Jepon Kabupaten Blora. Prosiding Seminar Nasional Unimus, 425-437.

Juhara, Y., Puannandini, D. A., \& Baskoro, N. E. (2018). Tinjauan Yuridis terhadap Pertimbangan Hukum Oleh Hakim dalam Putusan Perkara Nomor: 669/PID.SUS/2014/ PN.BLB Dihubungkan dengan Pasal 55 Undang-Undang Nomor 22 Tahun 2001 Tentang Minyak dan Gas Bumi. Pemuliaan Hukum, 1(1), 73-96.

Julkifli. (2019). Penegakan Hukum Penyalahgunaan Pengangkutan Bahan Bakar Minyak Bersubsidi di Provinsi Riau Berdasarkan Undang-Undang Minyak dan Gas Bumi. Gagasan Hukum, 1(1), 130-145.

Kalensang, A. J. (2016). Hubungan Sebab Akibat (Causaliteit) dalam Hukum Pidana dan Penerapannya dalam Praktek. Lex Crimen, 5(7), 12-19.

M. Ridwan, I. M. S., \& Fitriani, A. (2010). Analisis Kinerja Ekspor Impor Komoditi Peternakan di Sulawesi selatan. JITP, 1(1), 48-58.

Prihatini, W. (2013). Ekobiologi Kerang Bulu Anadara Antiquata di Perairan Tercemar Logam Berat. Jurnal Teknologi Pengelolaan Limbah, 16(12).

Randang, V. G. (2015). Pengembangan Pengaturan Pengangkutan Multimoda dalam Hukum Pengangkutan Niaga di Indonesia. Lex Administratum, 3(5), 2015.

Resalane, J., \& Hartiwiningsih. (2014). Kajian Terhadap Tindakan Pidana Pengangkutan Bahan bakar Minyak 
Tanpa Izin Usaha Pengangkutan. Recidive, 3(3), 334-344.

Rumokoy, N. K. (2016). Pelanggaran Hukum Terhadap Penggunaan Minyak dan Gas Bumi (Migas) yang Terkandung di dalam Wilayah Hukum Pertambangan Indonesia oleh Pihak yang Tidak Berwenang. Jurnal Hukum Unsrat, 22(5), 40-55.

Sang Ayu Putu Rahayu. (2017). Prinsip Hukum dalam Kontrak Kerjasama Kegiatan Usaha Hulu Minyak dan Gas Bumi. Yuridika, 32(2), 336-354. 